RAEIC, Revista de la Asociación Española de Investigación

\title{
La innovación de la Televisión Pública Europea en la oferta audiovisual digital: nuevas plataformas para la Generación Z
}

European Public Television's innovation in the digital audiovisual offer: new platforms for Generation Z

Francisco-Lens, Noelia Universidade de Santiago de Compostela (USC) noeliafranciscolens@gmail.com

Rodríguez-Vázquez, Ana-Isabel Universidade de Santiago de Compostela (USC) anaisabel.rodriguez.vazquez@usc.es

Forma de citar este artículo:

Francisco-Lens, N., y Rodríguez-Vázquez, A. I. (2020). “La innovación de la Televisión Pública Europea en la oferta audiovisual digital: nuevas plataformas para la Generación Z", RAEIC, Revista de la Asociación Española de Investigación de la Comunicación, vol. 7, núm. 13, 185-212 https://doi.org/10.24137/raeic.7.13.9

\section{Resumen:}

La revolución digital vivida en los últimos años ha obligado a las corporaciones de televisión a desarrollar nuevas estrategias de producción y difusión de contenidos. La apuesta por complementar su oferta lineal con otros servicios tiene la finalidad de 
adaptarse a los hábitos de consumo de las nuevas generaciones. En la presente investigación, por medio de un análisis de tipo exploratorio-descriptivo de tipo cuantitativo, se analizan durante el mes de octubre de 2019 las Televisiones Públicas Europeas que han desarrollado nuevas plataformas de difusión de contenidos originales como vía para atraer y fidelizar a los espectadores más jóvenes. El objeto de estudio se centra en las plataformas resultantes del análisis y en su oferta de contenidos. Los resultados muestran como algunos de los grupos televisivos europeos apuestan por adaptarse a los patrones de consumo de las nuevas generaciones, con una oferta paralela de contenido caracterizada por la participación, la interactividad y la multimedialidad, concebida para un consumo ágil y exclusivamente online.

Palabras clave: televisión pública, contenidos digitales, participación, innovación, interacción

\section{Abstract:}

The digital revolution experienced in recent years has forced television corporations to develop new strategies of content production and dissemination. The commitment to complement its main offer with other services aims to adapt television corporations to the consumption habits of new generations. In this investigation, through a quantitative exploraty-descriptive analysis we analize during the month of October 2019 European Public Television that have developed new platforms for the dissemination of original content as a way to attract and retain younger viewers. This study focuses on the platforms resulting from the analysis and their content offer. Results show that some of Europe's Television groups are committed to adapting to consumption patterns of new generations, and their content offer is characterized by participation, interactivity and multimediality, and designed for fast consumption and exclusively online.

Keywords: public television, digital contents, participation, innovation, interaction. 


\section{INTRODUCCIÓN}

Desde el inicio del proceso de digitalización y la aparición de Internet el sector audiovisual está inmerso en un proceso de transformación de sus formas de producción y difusión de contenido (García-Carrizo, 2016). Los grupos televisivos se intentan adaptar a la migración que la audiencia está realizando hacia nuevas formas de consumo cada vez más móvil, multidireccional y multidispositivo (Villarrubia, 2016) de unos contenidos audiovisuales caracterizados por su interactividad, multimedialidad y participación.

Son los nativos digitales los que más han cambiado sus pautas de consumo audiovisual, con una tendencia individualista, de consumo rápido, que pasa necesariamente por la conexión a Internet. Hablamos de audiencias activas que buscan en la televisión digital la posibilidad de participar e intervenir en los diferentes contenidos con la finalidad de no estar sujetos a estructuras tradicionales de la televisión lineal.

Las corporaciones televisivas apuestan por la innovación y el desarrollo de nuevas tecnologías para mejorar su oferta de contenidos complementarios a los televisivos tradicionales y conseguir así ese engagement con los espectadores más jóvenes. Para esto, crean diferentes estrategias, como puede ser el desarrollo de nuevas plataformas que emplean distintos dispositivos de acceso o contenidos con formato innovadores, con mayor posibilidad de participación e interacción del usuario.

\section{REVISIÓN DE LITERATURA}

\subsection{CAMBIOS EN EL TRADICIONAL PARADIGMA TELEVISIVO}

La transición de la televisión analógica a la digital y la convergencia entre redes, medios y dispositivos (Syvertsen, 2006) han ocasionado cambios fundamentales en el paradigma televisivo tradicional. El aumento de la oferta televisiva, el desarrollo de nuevas tecnologías o el incremento de los dispositivos de acceso permiten desligar el consumo televisivo de sus constricciones de tiempo y espacio (Prado, 2015). El consumo de televisión se convierte en un servicio personalizado e individualizado al que los usuarios tienen acceso en cualquier momento, lugar y a través de múltiples dispositivos. 
La conocida como televisión tradicional, lineal, con limitaciones de tiempo y espacio ya no satisface a las audiencias, que en el ámbito de la digitalización en el que estamos inmersos prefieren los medios basados en Internet (Arceo, 2017). Así pues, los medios televisivos están llevando a cabo nuevas estrategias y procesos productivos complementarios a los televisivos tradicionales. Para esto, se ayudan de la sinergia que la televisión establece con Internet, las redes sociales o los dispositivos móviles (González-Neira y Quintas-Froufe, 2016).

La convergencia de medios, la aparición de Internet o las redes sociales ha hecho posible que los usuarios puedan ser partícipes de los contenidos a través de diversas opciones de interacción con los mismos, como puede ser compartir fotos, realizar comentarios o incluso cambiar el rumbo de un capítulo de una serie. "There is a blurring line between the producer and the consumer but they have not necessarily shifted roles. Users have only been given a chance to become co-creators of the show" (Arceo, 2017, p.6).

El aumento del número de dispositivos y del número de usuarios con acceso a Internet supuso un cambio en los hábitos de consumo de contenido de las audiencias dando lugar a una personalización e individualización a la hora de la visualización de los mismos. Las audiencias se caracterizan por una conexión a la red permanente, que participa activamente en los contenidos que visualiza y que demanda un intercambio vertical y bidireccional de información entre el emisor y el receptor, y no solo una relación horizontal con otros usuarios (Quintas-Froufe y González-Neira, 2014).

González-Neira (2015) señala que "ha eclosionado un nuevo tipo de audiencia: diferida (ve la televisión cuando le apetece) y diseminada (usa el dispositivo más conveniente segundo el contexto" (p.22). Las audiencias, sobre todo las nuevas generaciones, se encuentran migrando de la televisión tradicional a nuevas plataformas de contenido basadas en Internet (como pueden ser YouTube, Netflix, HBO, Amazon Prime...) buscando la velocidad de la red, un entorno de mayor interactividad y participación y el acceso a los canales de forma limitada. Este panorama da lugar a una dispersión de las audiencias que cada vez son más difíciles de fidelizar. 
Debido al cambio de los consumos mediáticos y las nuevas formas de entretenimiento que modifican el tiempo que las audiencias destinan a los medios de comunicación de masas, las TV tradicionales buscan cómo ofertar el contenido de un modo más interactivo, participativo y con Internet como principal medio de difusión, a fin de captar y fidelizar esas audiencias que disponen de diferentes hábitos de consumo.

Las nuevas formas de acceso a los contenidos televisivos (IPTV, video on demand, over the top, servicios a la carta...) alteran la forma de producir contenido de los medios tradicionales, así como el modelo de negocio tanto de los programadores como de los distribuidores de contenidos. Así pues, todos los agentes que hay en el mercado empiezan a posicionarse en estas nuevas formas de producción y distribución de contenido en busca de ese engagement con las audiencias más jóvenes. Los grupos televisivos tradicionales intentan acaparar a este público a través de productos producidos para Smart TV, web TV, smartphones, redes sociales, etc., que permiten un consumo personalizado, participativo e interactivo. Este cambio a la hora de producir y difundir contenidos y programación original paralela a la televisiva tradicional viene también motivado por la necesidad de captar a ese público, pues se trata de un grupo demográfico cada vez más vital para la industria de la publicidad (Smith, 2018).

Las televisiones se están convirtiendo en grandes contenedores de contenido que presentan su oferta en distintas ventanas de recepción: televisión conectada, ordenadores, smartphones... Todo para ofrecer un modelo de televisión online más personalizado, interactivo y participativo, caracterizado por la distribución multiplataforma y los contenidos adaptados a cada dispositivo. En estos últimos años se avanzó también en nuevas plataformas con contenido original realizado y distribuido por Internet con un público objetivo muy claro: las nuevas generaciones digitales, y también con una finalidad: conseguir ese engagement con un público que cada vez se aleja más de la televisión.

\subsection{LAS NUEVAS GENERACIONES Y SUS HÁBITOS DE CONSUMO}

Son los nativos digitales los que más han cambiado sus pautas de consumo audiovisual, con una tendencia individualista, de consumo rápido, que pasa necesariamente por la 
conexión a Internet. Estos cambios en los hábitos de consumo de contenidos han motivado a los medios de comunicación tradicionales a modificar su forma de distribución de contenido y de conexión con los usuarios más jóvenes, apostando por la creación de plataformas multidispositivo (móvil, tableta, ordenador, TV conectada...) con nuevos formatos más interactivos y participativos y con productos audiovisuales a la carta.

Las audiencias más jóvenes no responden a la fórmula tradicional de la pasividad televisiva. Es un público cuyas preferencias audiovisuales van más allá del contenido realizado por profesionales, por lo que acuden a plataformas donde pueden visualizar contenido amateur (Guerrero, 2018). Hablamos de audiencias activas que buscan en la posibilidad de participar, intervenir e interactuar en los contenidos que visualizan. Por esto, las corporaciones televisivas se plantean reestructurar las relaciones tradicionales establecidas con sus receptores a través de diversas estrategias como es el desarrollo de nuevas plataformas, con características como la multimedialidad, interactividad, personalización de los contenidos, etc.

En este punto, cabe definir donde podemos comenzar a hablar de las nuevas generaciones y cuáles son sus características. No existe un consenso definitivo en cuanto a datas de inicio y fin para nombrar a las generaciones más jóvenes. Pew Research Center decidió establecer el año 1996 como el último año de nacimiento de los Millennial "Anyone born between 1981 and 1996 (ages 23 to 38 in 2019) is considered Millennial, and anyone born from 1997 onward is part of a new generation" (Dimock, 2019).

Neil Howe y William Strauss (2000) definía la generación Millennial entre aquellas nacidas entre el 1985 y el 2000, mientras que otros informes como el del grupo Barlovento (2016) en España sitúan esta generación entre aquellas personas que nacieron entre el 1980 y el 1995. Otras instituciones como Deloitte (2019) hablan de otras fechas, llamando a esta generación, generación Y o Millennials a los nacidos entre el 1983 y el 1994. Algunos expertos acuñaron otras denominaciones para referirse a los adolescentes que tienen hábitos de consumo caracterizados por la conexión a Internet 
y el consumo rápido de contenidos, como es el caso de la llamada Net Generation (Fernández-Planells y Figueras, 2014) o de los nativos digitales (Prensky, 2001).

Tras la llamada generación Millennial se comienza a hablar de otra generación refiriéndose a la misma como la verdadera nativa digital y que se consolida como la Generación Z "But over the past year, Gen Z has taken hold in popular culture and journalism. Sources ranging from Merriam-Webster and Oxford to the Urban Dictionary now include this name for the generation that follows Millennials, and Google Trends data show that "Generation Z" is far outpacing other names in people's searches for information. While there is no scientific process for deciding when a name has stuck, the momentum is clearly behind Gen Z" (Dimock, 2019). Como se puede comprobar los puntos de corte de las generaciones no es una ciencia exacta "they should be viewed primarily as tools, allowing for the kinds of analyses detailed above" (Dimock, 2019).

Pew Research Center (2019) establece el año 1996 como fin de la generación Millennial por varios factores políticos, económicos y sociales. Como políticos el atentado al World Trace Center el 11 de septiembre del 2001 o las guerras de Irak y Afganistán, acontecimientos que en Estados Unidos marcaron el entorno político. Estos acontecimientos quedaron en la memoria de la llamada generación Millennial, mientras que la Generación Z ya no ha vivido estos actos y apenas tiene recuerdos. Por otro lado, la mayoría de los Millennials tenían entre 12 y 27 años cuando en el 2008 se eligió al primer presidente negro en Estados Unidos y donde el voto juvenil tuvo mucha fuerza.

Figura 1. Las generaciones definidas.

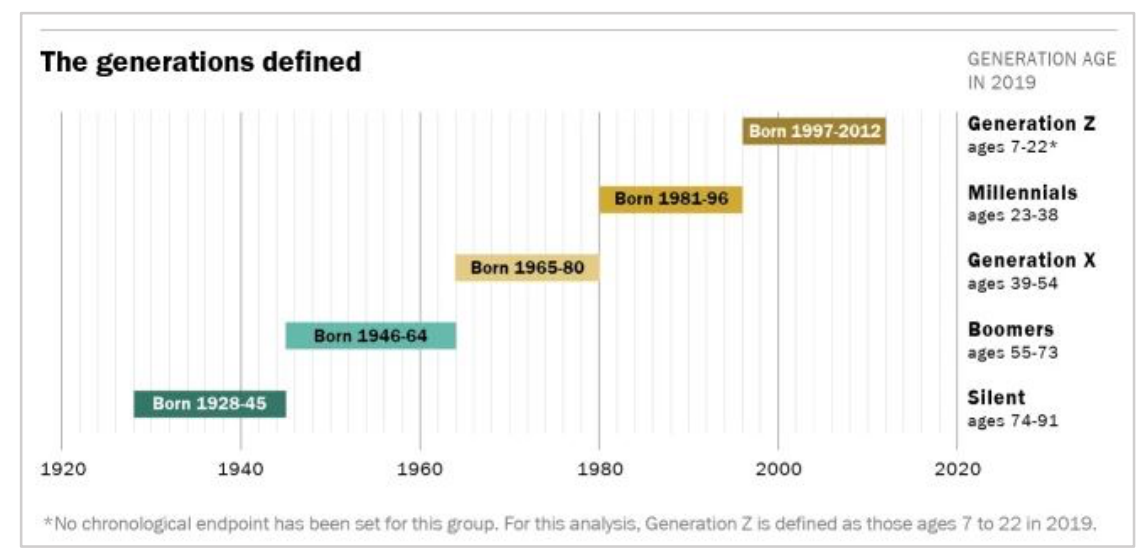

Fuente: Pew Research Center (2019). 
Tanto los Millennials como la Generación Z, tienen similitudes y diferencias, que provienen debido a las diferentes edades y al proceso tecnológico en el que se vieron involucradas pues, por ejemplo, mientras que la Generación Z nació en un mundo definido por el uso de Internet, la generación Millennial ha visto como esta nueva forma de comunicación modificaba sus hábitos de consumo poco a poco.

Si nos centramos en las características de la Generación Z, destacamos que esta generación está más conectada a las nuevas tecnologías y a Internet, emplea la mensajería instantánea, el correo electrónico y las redes sociales, considerándose audiencias sociales ya que comparten los contenidos y su experiencia de visionado.

Figura 2. Consumo de redes sociales en móviles en la Generación Z y Milennials.

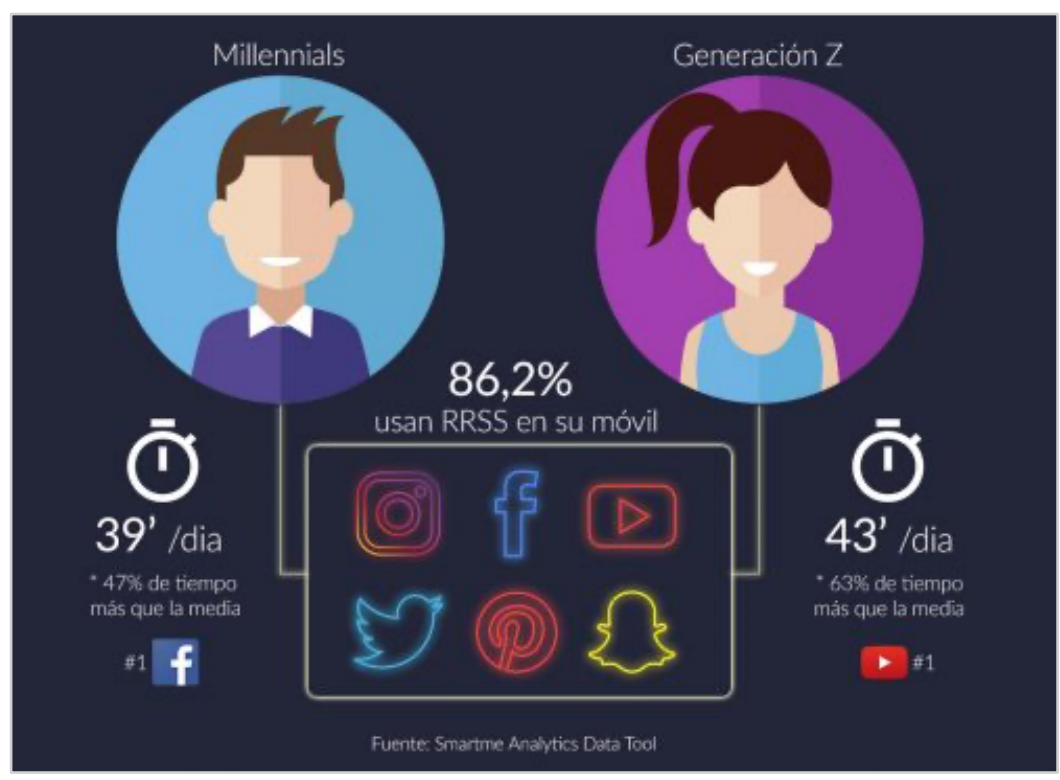

Fuente: Startme Analytics Data Tool (2017).

El consumo de la Generación Z está dominado por lo digital, y su principal forma de acceso a Internet es el móvil. Según datos de Kantar Millward Brown (2017), un 74\% se conectan a Internet a través del móvil al menos una vez al día, un $14 \%$ más que los Millennials. Además, el consumo de los medios tradicionales es menor si lo comparamos con el resto de las generaciones. En el caso de la televisión, alrededor de un 60\% declara que ve una hora o más la televisión al día comparado con el $81 \%$ de los llamados Millennials (Kantar Millward Brown, 2017). 
La Generación Z prefiere Internet a la televisión convencional, pues busca participar y fomentar la interacción con los contenidos que consume, haciendo un consumo la mayoría de las veces complementario de los dos medios, creando del acto de ver la televisión una experiencia más personal. La televisión tradicional, pasiva, tal y como era antes, ya no atrae a los llamados nativos digitales pues no ofrece novedades con respecto a la oferta de siempre. Las nuevas generaciones responden a nuevos hábitos de consumo motivados por la multiplicación de pantallas y la aparición de contenidos fragmentados. Demandan que los contenidos televisivos se puedan visualizar en otros dispositivos y que sean innovadores en los formatos. Son audiencias activas, que buscan en la televisión digital la posibilidad de participación e interacción con los contenidos y la posibilidad de visionarlos cuando ellos deseen, sin estar sujetos a estructuras tradicionales.

Los medios tradicionales se adaptan a las nuevas prácticas de visualización de los jóvenes espectadores dando lugar al desarrollo de nuevos contenidos diferenciados, apps para smartphones, contenidos participativos, interactivos y multimedia para sus webs... "The media landscape is changing at a fast pace and moving in the direction where traditional and new media have no choice but to coexist" (Arceo, 2017, p.2). Autores como Scolari (2008) se refieren a esta nueva etapa de la televisión con el térmico de "hipertelevisión" para catalogar una nueva era caracterizada por la expansión de sus historias a través de diferentes medios y las narraciones transmedia. A estas propiedades Scolari suma otras como la aparición de lógicas colaborativas de los usuarios, el desenvolvimiento de las nuevas formas de consumo asincrónicas o la difusión de la TV móvil.

En este contexto, los operadores tradicionales están casi obligados a desarrollar estrategias que enriquezcan la experiencia televisiva de los usuarios, que optan por un consumo de televisión diferente al consumo pasivo tradicional buscando nuevas experiencias de visualización. Para esto completan su oferta programática con otros servicios o incluso desarrollan contenidos diseñados específicamente para la Generación Z. 


\section{METOdOLOGÍA}

El presente trabajo analiza las Televisiones Públicas Europeas que forman parte y son activos miembros de la Unión Europea de Radiodifusión (EBU) a día 1 de agosto de 2019, para detectar aquellas que desarrollaron nuevas plataformas de difusión de contenido original y totalmente online como vía para atraer y fidelizar a los espectadores más jóvenes, concretamente a la Generación Z. Se pretende ver la adaptabilidad de las Televisiones Públicas Europeas para desarrollar plataformas de contenido adaptado a las nuevas formas de visualización de esta generación, y sus estrategias de engagement.

En total se analizaron a 70 grupos televisivos públicos europeos que representan a 116 organizaciones en 56 países (EBU, 2019). El objeto de estudio se centra en las plataformas resultantes del análisis (webs u otras plataformas de visualización de contenidos) y en su oferta de contenidos en el mes de octubre del 2019.

A la hora de realizar el análisis de las plataformas resultantes de la observación de las Televisiones Públicas Europeas pertenecientes a la EBU se tuvieron en cuenta diversos estudios previos que llevaron a cabo análisis de páginas webs televisivas y propusieron una serie de parámetros para su observación. Es el caso de la propuesta de análisis realizada por Codina, Aubia y Sánchez (2008), las categorías definidas por Crusafón (2011) para el análisis de las estrategias en nuevas plataformas digitales de cadenas de televisión, los indicadores para la evaluación de la calidad en los cibermedios propuesta por Rodríguez-Martínez, Codina y Pedraza-Jiménez (2012) y las variables de análisis de los contenidos realizada por García-Carrizo (2016).

Se ha recurrido al análisis de diferentes variables para establecer un parámetro de análisis en cada plataforma. Estas variables han sido:

- Contenidos ofertados: descripción del tipo de contenido ofertado en función del género

- Servicios multiplataforma: oferta de contenido en diferentes pantallas

- Suscripción y creación de perfil: personalización de los contenidos 
- Participación de usuarios: posibilidad de que los usuarios interaccionen con el contenido a través de comentarios u otras acciones, publicación de contenidos creados por los usuarios (UGC), interacción del usuario con el medio de comunicación, existencia de comunidades

- Social networking: presencia y actividad en las redes sociales más populares (Instagram, Facebook y Twitter). Se analiza el grado de interacción con los usuarios en función de los seguidores

\section{ANÁLISIS}

Tras el análisis de los diferentes grupos televisivos públicos en Europa, partiendo de su página web corporativa para comprobar su oferta digital para captar aquellas plataformas, canales o productos enfocados en las generaciones más jóvenes, se comprueba que las televisiones públicas están en proceso de mejora de su oferta online, siendo conscientes de las nuevas formas de consumo que se están adoptando, y su consiguiente progresiva bajada del consumo lineal de la televisión tradicional. La mayoría de los grupos televisivos disponen de su propia plataforma de vídeo para ver los contenidos audiovisuales en directo y a la carta de sus canales lineales.

Figura 3. Captura de pantalla de RaiPlay de la Radiotelevisión Italiana (RA/).

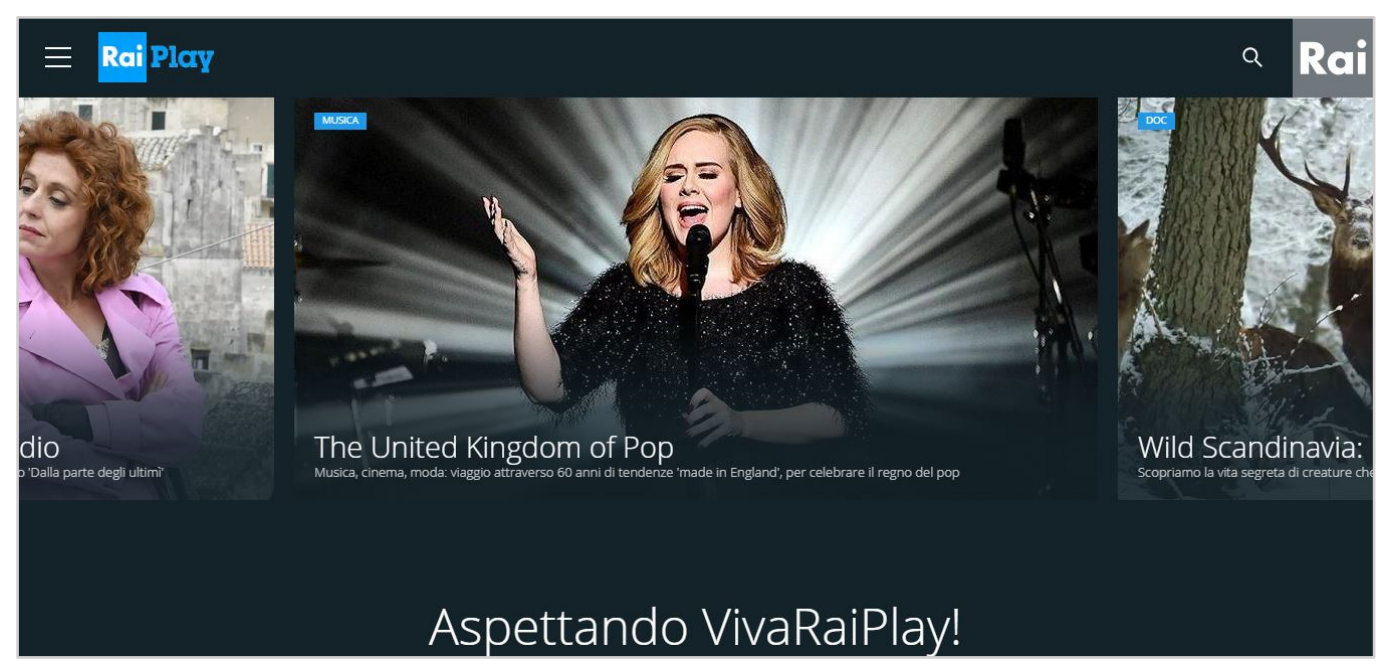

Fuente: https://www.raiplay.it/

En diferentes países se ha podido observar la existencia de plataformas con oferta de contenido paralela a la televisiva tradicional, dirigida a las nuevas generaciones. Es el 
caso de la Radiotelevisión Pública Española (RTVE) que en el año 2017 crea la plataforma Playz. RTVE define Playz como la plataforma de televisión en Internet para rejuvenecer a las audiencias y apostar por nuevos talentos. Se trata de un nuevo espacio digital en abierto con contenidos originales e interactivos para los nuevos públicos. Grandes creadores digitales y nuevas formas de contar a través de la interactividad y el transmedia son los ingredientes principales de esta plataforma.

Los contenidos son totalmente originales, producidos específicamente para esta plataforma. Ficción a través de webseries, programas de entretenimiento, música, podcasts y documentales de actualidad son algunos de los géneros que podemos encontrar en esta plataforma en la que los jóvenes son los protagonistas. A través de su menú ya podemos observar algunos de los contenidos que ofrece Playz: Webseries, Urbana (espacio de Playz dedicado a la música y a la cultura urbana, que da inicio con el estreno de Héroes, una serie de microdocumentales dedicados a las principales figuras del skate en España), Tube (donde se reúnen contenidos en diferentes canales copiando el formato YouTube). En el menú también destaca la pestaña APP, para que los usuarios sepan que pueden disfrutar de los contenidos de Playz donde quieran y como quieran.

Playz se caracteriza por realizar productos innovadores experimentando con los nuevos formatos. Es el caso de Cam on! el primer talent show de fotografía transmedia en España. En este talent show cinco reconocidos influencers españoles se enfrentan a seis retos fotográficos utilizando algunos de los hashtags más populares en Instagram (\#Art, \#Happy, \#Fashion, \#Nature, \#Love y \#Me) en los que un jurado profesional evalúa a los participantes, mientras que el público podrá votar sus fotos favoritas en el Instagram de @playz.

En la web de Playz los usuarios no pueden comentar, pero si pueden compartir el contenido en Facebook y Twitter y copiar el enlace del vídeo que quieran difundir. No cuenta con la opción de crear un perfil para personalizar los contenidos o poder crear una comunidad en la web. Playz está presente en Facebook (14.909 seguidores), en Instagram (45.759 seguidores) e Twitter (228.618 seguidores). La red social Instagram también se emplea para crear contenido exclusivo de series o programas, o realizar test 
y cuestionarios para que los usuarios puedan incluso decidir el contenido de una serie. Los espectadores pueden comunicarse con el medio a través de correo electrónico o con mensajes en los distintos perfiles de las redes sociales. Playz también está presente en YouTube, donde sube íntegramente la mayor parte de los programas que produce.

Figura 4. Captura de pantalla de Playz de la Radiotelevisión Española (RTVE).

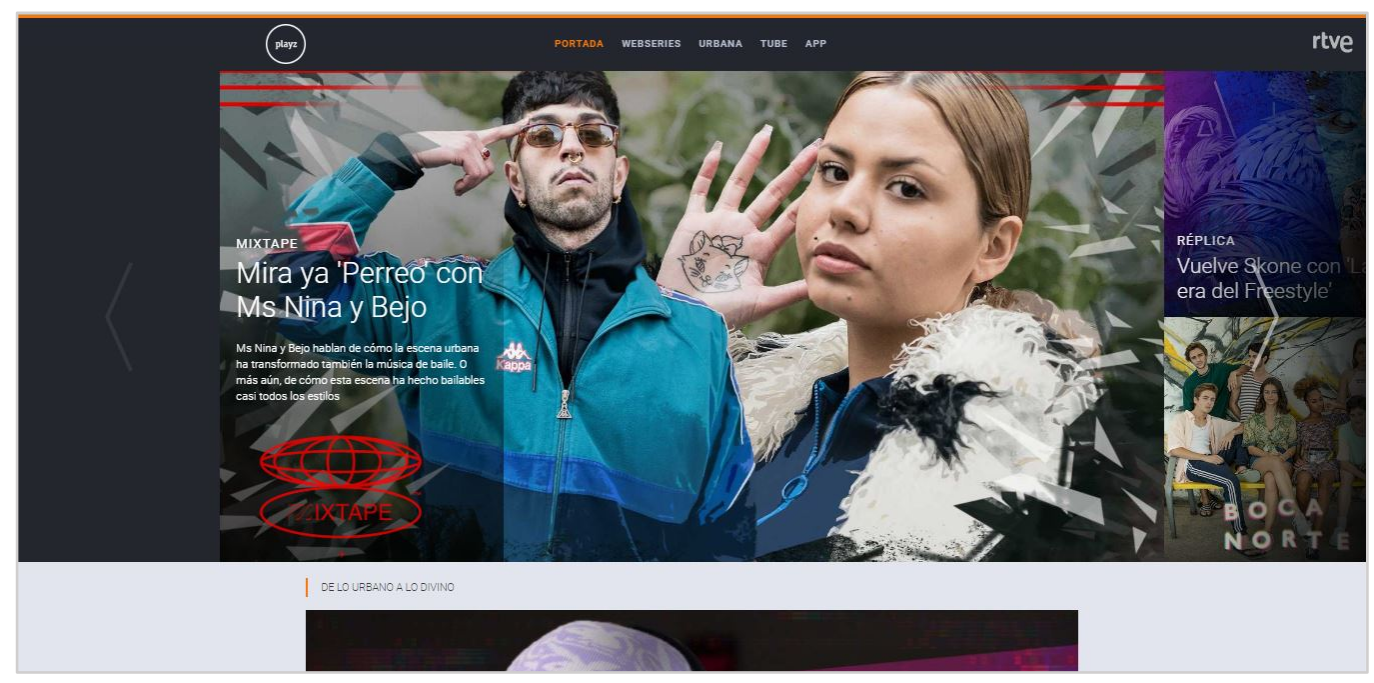

Fuente: http://www.rtve.es/playz/

La Radio y Televisión de Portugal (RTP) ha desarrollado también una serie de productos dirigidos a las generaciones más jóvenes gracias a RTP Lab, un laboratorio creativo y experimental con nuevas formas de producción de contenido, diseñado en una lógica multiplataforma. RTP Lab nace para estimular la creatividad y la innovación, y para experimentar formas de producción de contenido, dando lugar a series de ficción y humor que emplean nuevas narrativas en ambientes exclusivamente digitales.

Algunos de los proyectos audiovisuales desarrollados gracias al laboratorio de RTP han sido: Amnésia, un thriller que cuenta la historia de una Blogger de éxito que una mañana se despierta con su novio muerto a su lado, disponible en RTP Play, YouTube e Instagram, red social en la cual se publicaba diariamente contenido que permitía reconstruir el pasado de la relación entre la pareja; \#CasaDoCais, serie de comedia que relata historias sin tabúes sobre cinco jóvenes que comparten casa en Lisboa, disponible en RTP Play y YouTube; o Appaixonados, una comedia romántica interactiva donde el público realiza el papel de cupido eligiendo la próxima cita que tendrá Ana, disponible 
en RTP Play, YouTube y la APP in Love, donde cualquiera podrá participar en la escritura de la serie y decidir el destino romántico de Ana.

En RTP Lab podemos encontrar todos los contenidos producidos en la pestaña "Projetos". No obstante, vemos que para su visualización completa tenemos que acudir a RTP Play o YouTube ya sea en el canal de YouTube de RTP o en el propio canal desarrollado exclusivamente para una serie o programa en concreto. Los productos se pueden ver en diferentes pantallas (móvil, TV conectada, Tablet, ordenador...). RTP Play permite compartir los contenidos en diferentes plataformas o copiar el enlace del contenido para su publicación, cuenta también con una subscripción de notificaciones. No obstante, no permite crear un perfil o personalizar la visualización de los contenidos a través de la creación de listas.

Podemos comprobar como la mayoría de los productos audiovisuales mencionados tienen cuentas en las principales redes sociales como es el caso de \#CasaDoCais con 8.936 seguidores en Instagram, 2.470 seguidores en Facebook y 2.001 en Twitter. A estos productos audiovisuales también se hace referencia en las redes sociales de RTP que cuenta con 101.824 seguidores en Instagram, 395.942 seguidores en Facebook y 493.423 seguidores en Twitter.

Figura 5. Captura de pantalla de RTP Lab de la Radio y Televisión de Portugal (RTP).

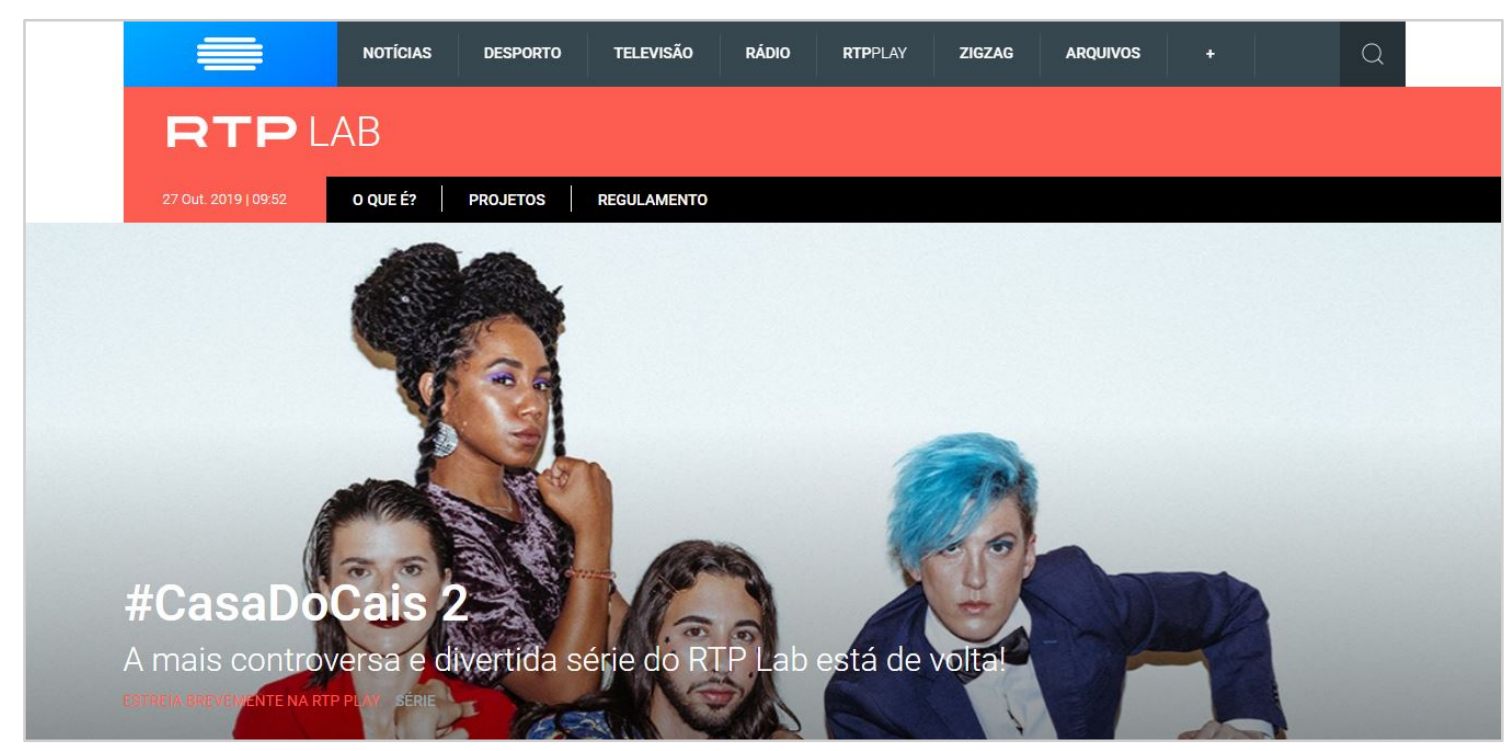

Fuente: $\underline{\text { http://media.rtp.pt/rtplab/ }}$ 
El grupo de Radiodifusión Francés (GRF) sorprende con una amplia oferta para las nuevas generaciones. En noviembre del año 2018 crea la plataforma France.tv Slash, una plataforma digital y gratuita dirigida a los jóvenes de 18 a 30 años, disponible en las plataformas de France TV, YouTube, Instagram, Facebook, Twitter y Snapchat. France.tv Slash cuenta con vídeos con un tono desenfadado, ligero y de corta duración. El canal está dirigido a jóvenes, abordando temas como: formación y trayectorias profesionales, discriminación, sexualidad, identidad... ofreciendo géneros como series, documentales, animación, humor o entrevistas.

France.tv Slash se lanzaba con Skam France, una serie que sigue la vida de varios adolescentes. Cada temporada de Skam France se centra en un personaje y en un tema. Los clips se publican en france.tv y en YouTube. Los espectadores también pueden seguir a los personajes a través de Instagram. France.tv Slash permite crear un perfil en la plataforma para suscribirse a los contenidos y crear listas. No permite realizar comentarios ni compartir el contenido en redes sociales directamente, aunque si puedes copiar el enlace del vídeo para poder compartirlo.

Figura 6. Captura de pantalla de France.tv Slash del grupo de Radiodifusión Francés (GRF).

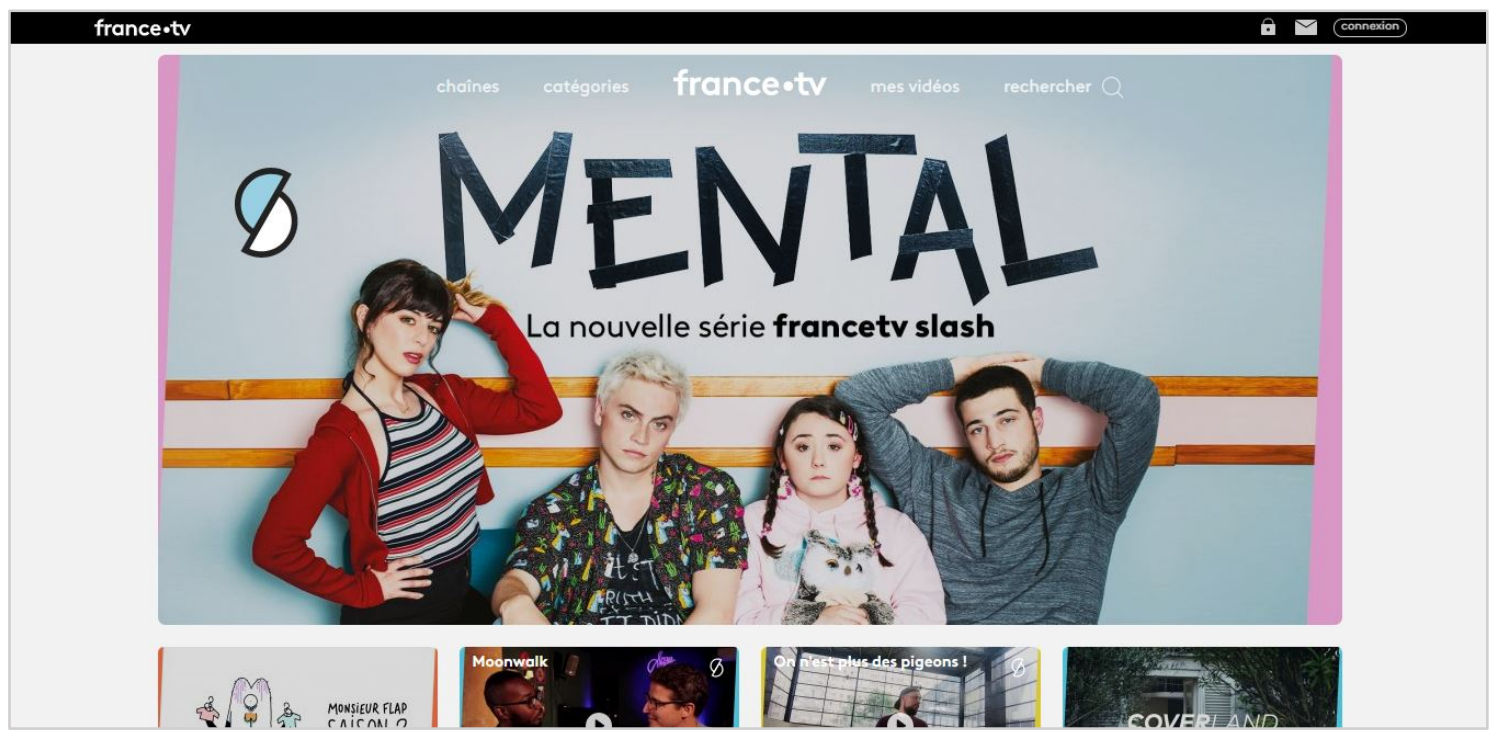

Fuente: https://www.france.tv/slash/

La televisión pública de Bélgica, Vlaamse Radio- en Televisieomroep o VRT ha desarrollado la plataforma MNM con el objetivo de involucrar a las generaciones más 
jóvenes. MNM es un canal que ofrece sobre todo música de éxito, pero el canal juvenil también desarrolla contenido audiovisual, como son noticias adaptadas a los jóvenes a través de vídeos de quince segundos que se publican todos los días a través de las plataformas de medios sociales como Facebook, YouTube e Instagram y presta atención a temas sociales en un programa y sitio web llamado Generación M. Estamos ante una plataforma con una oferta variada pero con un lazo y objetivo en común, atraer a las nuevas generaciones de la sociedad flamenca.

MNM permite crear un perfil para suscribirse a la web y recibir todas las novedades, además también cuenta con un APP para Apple y Android. No se permite realizar comentarios ni compartir los contenidos directamente desde la plataforma. MNM está presente en las redes sociales más importantes como Instagram (119.509 seguidores), Facebook (232.371 seguidores) y Twitter (152.406 seguidores).

Figura 7. Captura de pantalla de MNM de VRT.

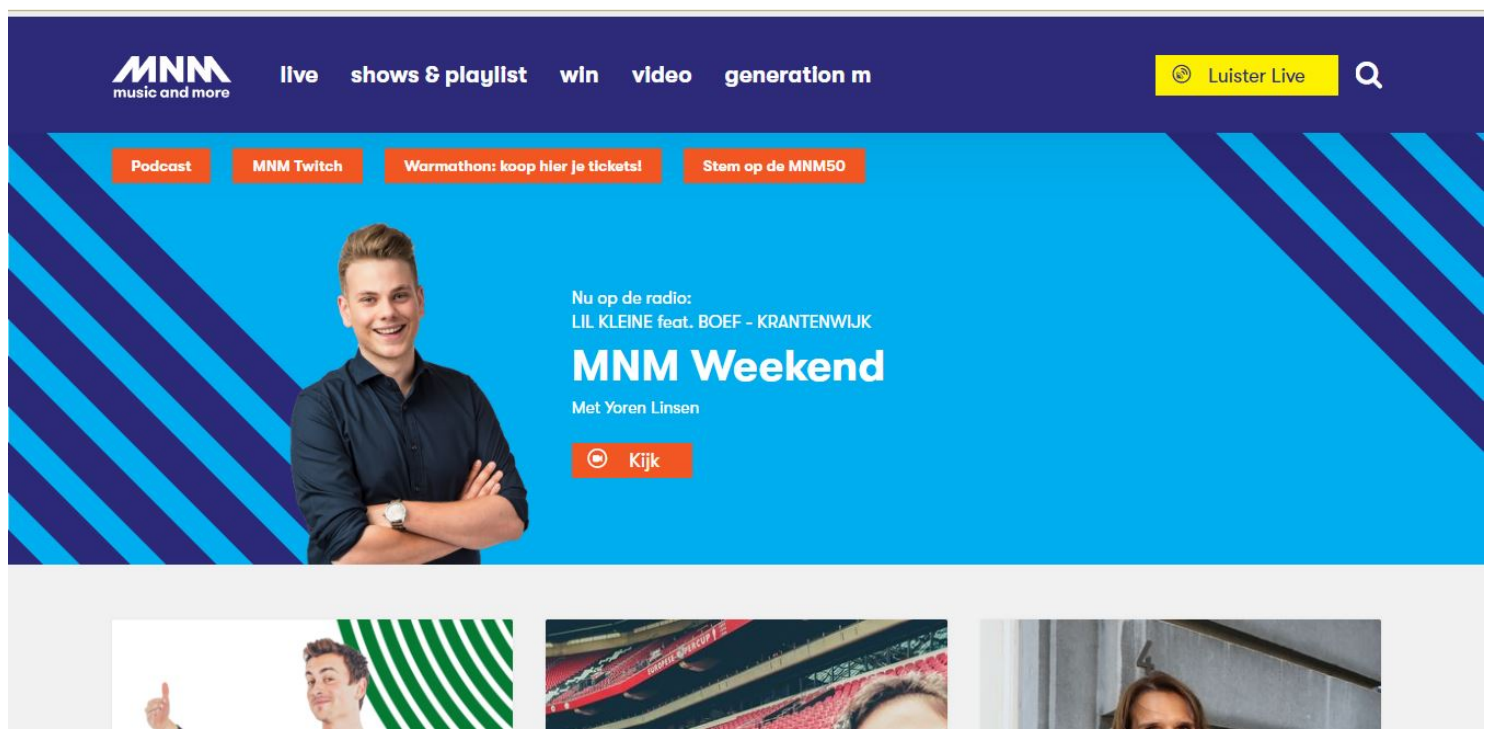

Fuente: $\underline{\text { https://mnm.be/ }}$

La Radio Télévision Belge de la Communauté français (RTBF) desarrolla una plataforma dirigida al público objetivo de este análisis: Webcréation. Un proyecto que nace con el objetivo de responder a los nuevos hábitos de consumo del público más joven produciendo y distribuyendo creaciones diseñadas para la web, redes sociales y múltiples soportes, creando nuevas comunidades al ofrecer experiencias enriquecidas en términos de interactividad y compromiso. 
RTBF Webcréation se organiza en torno a diferentes áreas de contenidos: las webseries ofrecen historias de todos los géneros (ficción, humor...) como es el caso de Boldiouk \& Bradock o \#PLS; destacan también las experiencias transmedia como Élèves en liberté o Guerre de Prank; cabe destacar también los documentales webs que exploran la información para ampliar temas de interés como es el caso de Los in Traplanta o Les nouveaux pauvres; por último, podemos encontrar experiencias en Realidad Virtual y 360 ․ Otro contenido al que podemos acceder a través de Webcréation son podcast sobre diferentes temas de interés para las nuevas generaciones.

RTBF busca también a los creadores del futuro, por eso a través de Webcréation realiza convocatorias de proyectos, para localizar a los nuevos generadores de contenido y producir los contenidos que consideran de mayor interés, permitiendo incluso a los usuarios de Internet elegir que producto audiovisual desean ver.

A la hora de visualizar los contenidos se redirige al espectador a la web de RTBF Auvio, la página de visualización de contenido a la carta de RTBF. Para ver el contenido es necesario crear un perfil a través de un registro que permite al usuario descubrir contenido relacionado con sus intereses, administrar favoritos, habilitar el control parental de los contenidos, entrar en concursos, gestionar boletines de información y mantenerse informado por correo electrónico.

No se permite comentar en los diferentes vídeos en la plataforma de Auvio pero si compartir en distintas redes sociales, o establecer un criterio de valoración a través de likes. RTBF Webcréation dispone de Facebook (7.280 seguidores), Twitter (1.763 seguidores) e Instagram (1.298 seguidores). 
Figura 8. Captura de pantalla de Webcréation de RTBF.

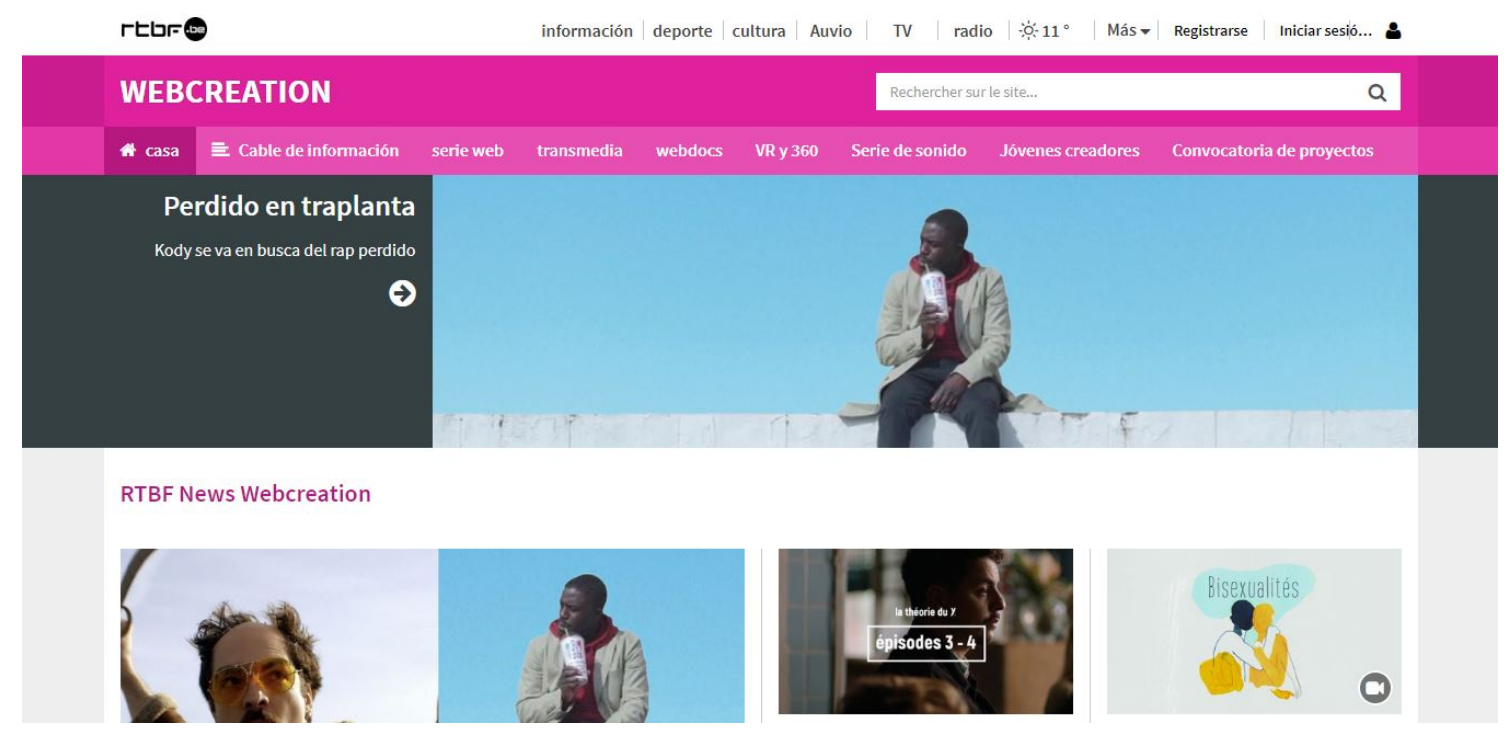

Fuente: https://www.rtbf.be/webcreation/

La Televisión Pública de Finlandia, la Oy Yleisradio Ab (YLE), cuenta con una plataforma de creación de vídeos cortos llamada Shortland a través de un concurso que procura la participación de los creadores finlandeses. Los vídeos son publicados en su canal de YouTube y en la propia plataforma. Los contenidos que encontramos en Shortland se caracteriza por su formato innovador, con una duración corta y con temas de interés para un público joven.

Para ver los vídeos los usuarios se tienen que redirigir a la página de visualización de contenidos de YLE. En esta plataforma el usuario puede crear un perfil para tener una experiencia de usuario más personalizada, con la posibilidad de seguir viendo un contenido donde lo dejó en cualquier momento y en cualquier dispositivo, agregar programas a favoritos o participar en encuestas y concursos. Shortland cuenta con Facebook (41 seguidores). 
Figura 9. Captura de pantalla de Shortland de YLE.

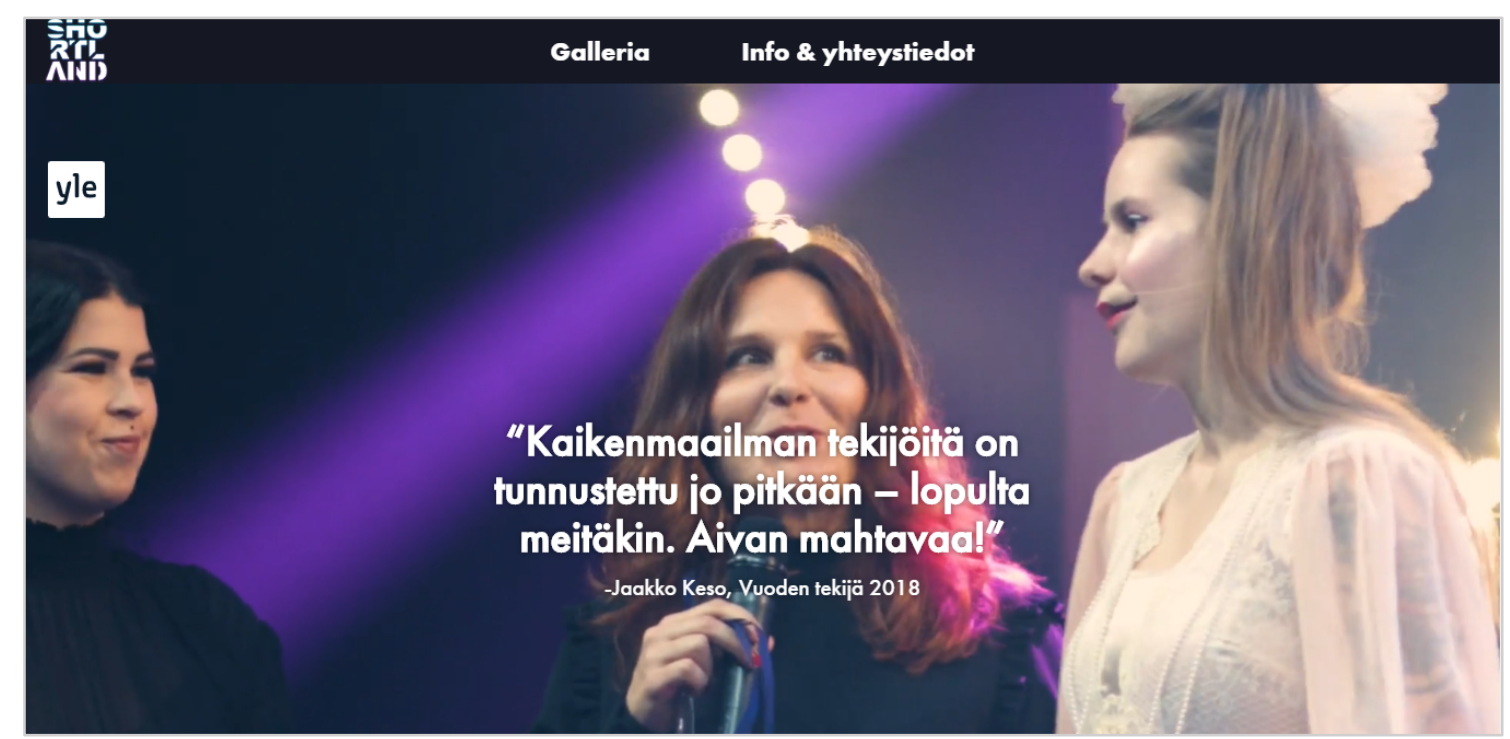

Fuente: $\underline{\text { https://shortland.fi }}$

Las dos televisiones públicas de Alemania, ARD y ZDF, se aliaron para crear Funk, una plataforma totalmente digital dirigida a jóvenes de entre 14 a 29 años que produce contenido de diferentes formatos. Vídeos de entretenimiento, informativos y críticos en 80 canales y 22 webseries de diferentes temáticas que se encuentran en Funk.net pero también en YouTube, Facebook, Instagram y Snapchat.

En Funk no existe la posibilidad de crear un perfil para personalizar la visualización de los contenidos, pero si permite activar una alerta para informar al usuario sobre el estreno de nuevos formatos o series. También cuenta con la función de búsqueda. El contenido se agrupa en canales, series y listas de reproducción en función de diferentes temáticas (últimos vídeos, darktube, trending, música, comedia, política y opinión, etc.).

Funk cuenta con un canal en YouTube con 68.300 suscriptores, una cuenta en Instagram con 12.611 seguidores y una cuenta en Facebook con 109.112 seguidores. 
Figura 10. Captura de pantalla de Funk de $A R D$ y $Z D F$.

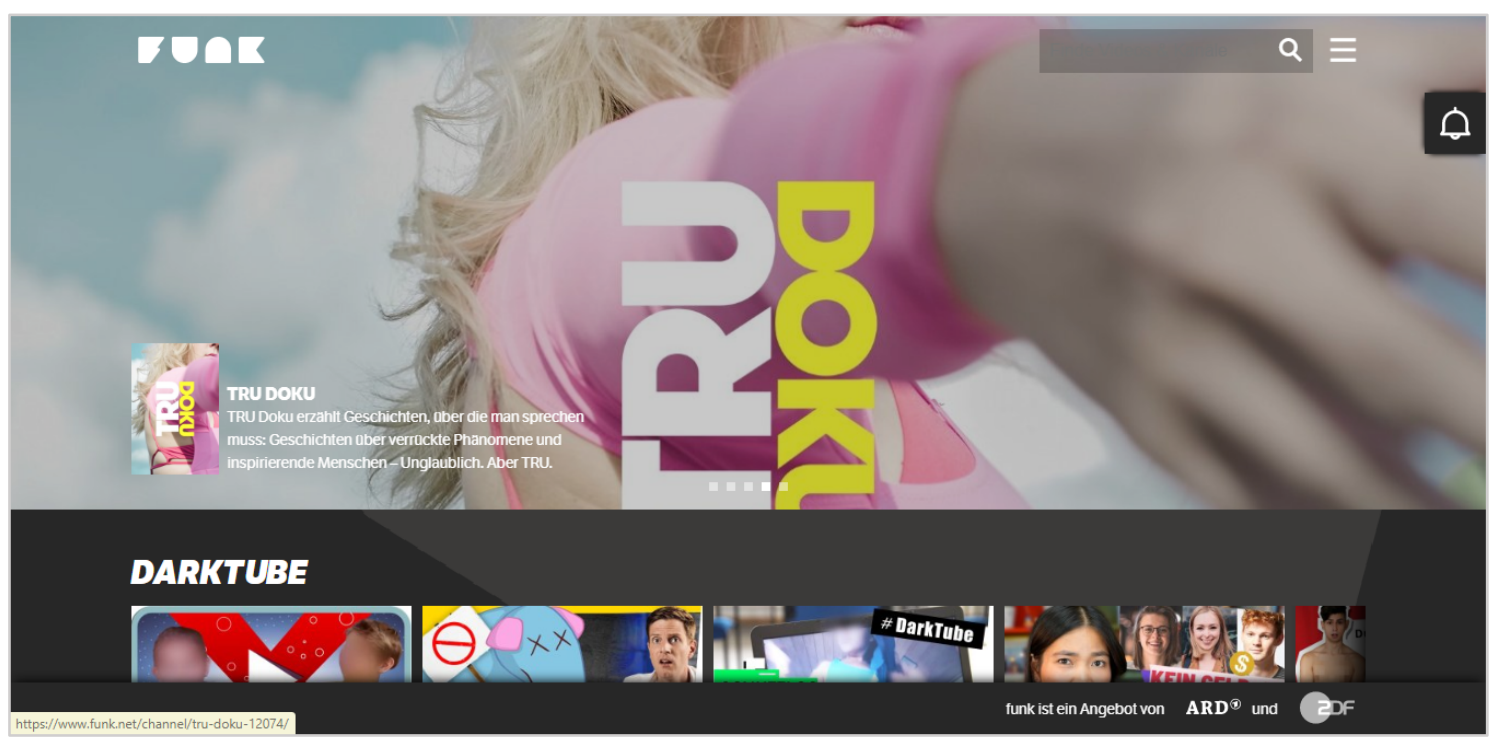

Fuente: https://www.funk.net/

La televisión pública de los Países Bajos, Nederlandse Publieke Omroep (NPO) dispone de varios grupos de televisión que desarrollaron una oferta exclusiva para el público más joven con formatos innovadores. Es el caso de NPO3, que desarrolla la plataforma 3LAB donde encontramos contenidos originales online como webseries, películas interactivas, programas periodísticos, documentales, programas de entrevistas o concursos. Es una plataforma que además está en la búsqueda activa de nuevos creadores jóvenes, con ideas frescas e innovadoras.

Los contenidos de 3LAB están disponibles en la página web de NPO3 y también en el canal de YouTube 3LAB. En la página web de NPO3 los contenidos se pueden compartir en Facebook, Twitter y por email y también a través del enlace del contenido. En la plataforma no se puede realizar ningún tipo de comentario o cualquier acción de interacción con el contenido. Para este propósito 3LAB cuenta con perfil en Facebook (4.860 seguidores) y Twitter (975 seguidores).

VPRO, otro canal de NPO, ha creado VPRO Dorst, un joven laboratorio de desarrollo de contenidos. Un espacio donde los nuevos talentos pueden enviar sus ideas y productos y probar nuevas formas de programación y de contar historias. El objetivo de VPRO es 
doble: permitir que nuevos talentos fluyan a través de VPRO y desarrollar formatos de programas exitosos que atraigan a la audiencia más joven de la emisora pública.

VPRO Dorst cuenta con contenido variado como son los documentales cortos o transmedia, las webseries de ficción, los podcasts o los programas de entrevistas. En la plataforma no se puede crear un perfil por lo que no existe una comunidad, pero sí se pueden compartir los contenidos. VPRO Dorst cuenta con perfil en Instagram (10.085 seguidores), Facebook (50.211 seguidores) y un canal en YouTube con 9.570 suscriptores.

Figura 11. Captura de pantalla de VPRO dorst de NOP.

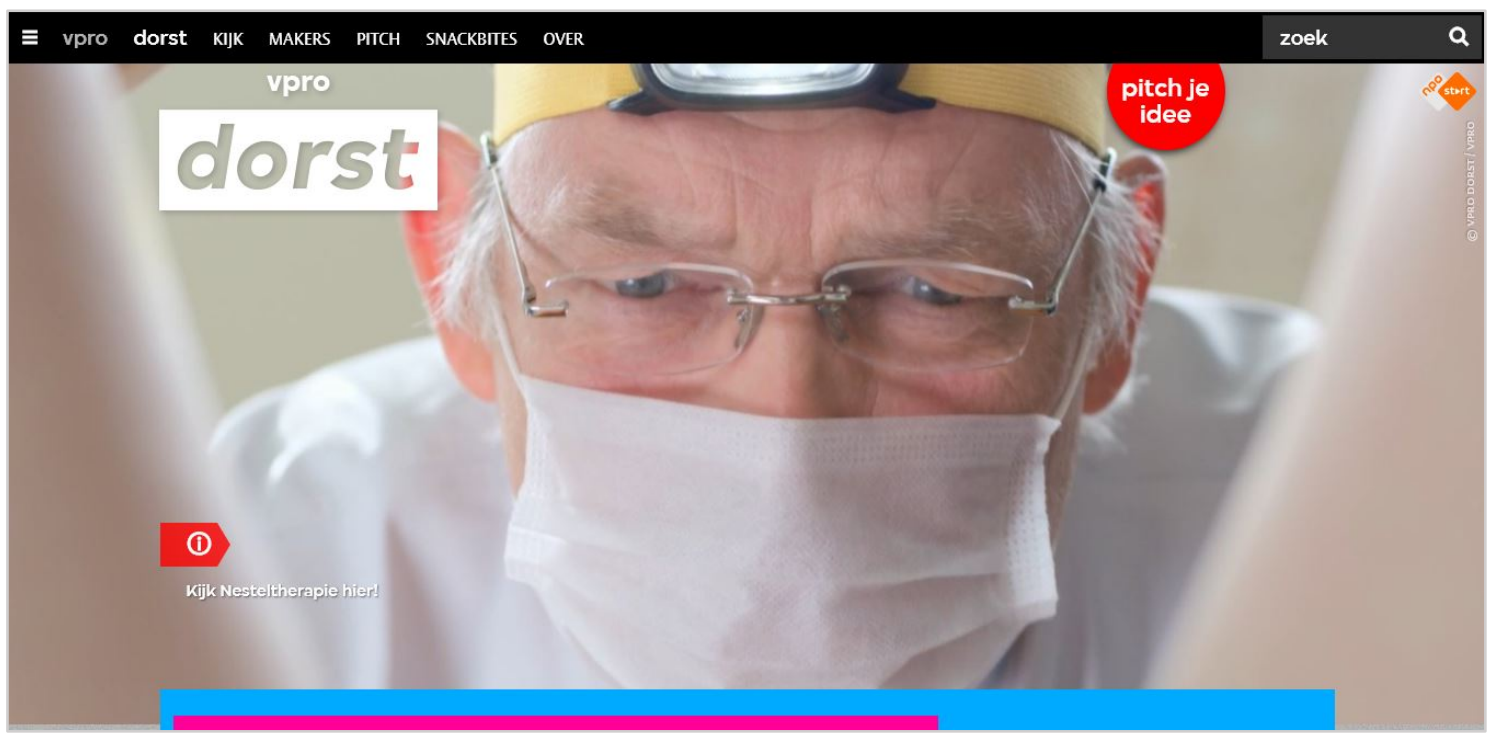

Fuente: https://www.vpro.nl/dorst.html

La televisión de Suecia, Sveriges Television (SVT), también ha desarrollado en su página de visualización de contenido a la carta SVT Play, una sección de YouTubers y jóvenes creadores, con formatos innovadores, transmedia y basados en redes sociales.

La plataforma SVT Play permite compartir los contenidos, pero no permite realizar comentarios. Tampoco permite la creación de un perfil en la plataforma para personalizar la visualización. SVT cuenta con APP para facilitar el acceso a los contenidos en diferentes pantallas y también con perfiles en las principales redes sociales: Instagram (117.775 seguidores), Facebook (405.812 seguidores) y Twitter (58.339 seguidores). Dispone también de un canal de YouTube con 50.900 suscriptores. 
Figura 12. Captura de pantalla de SVT Play YouTubers.

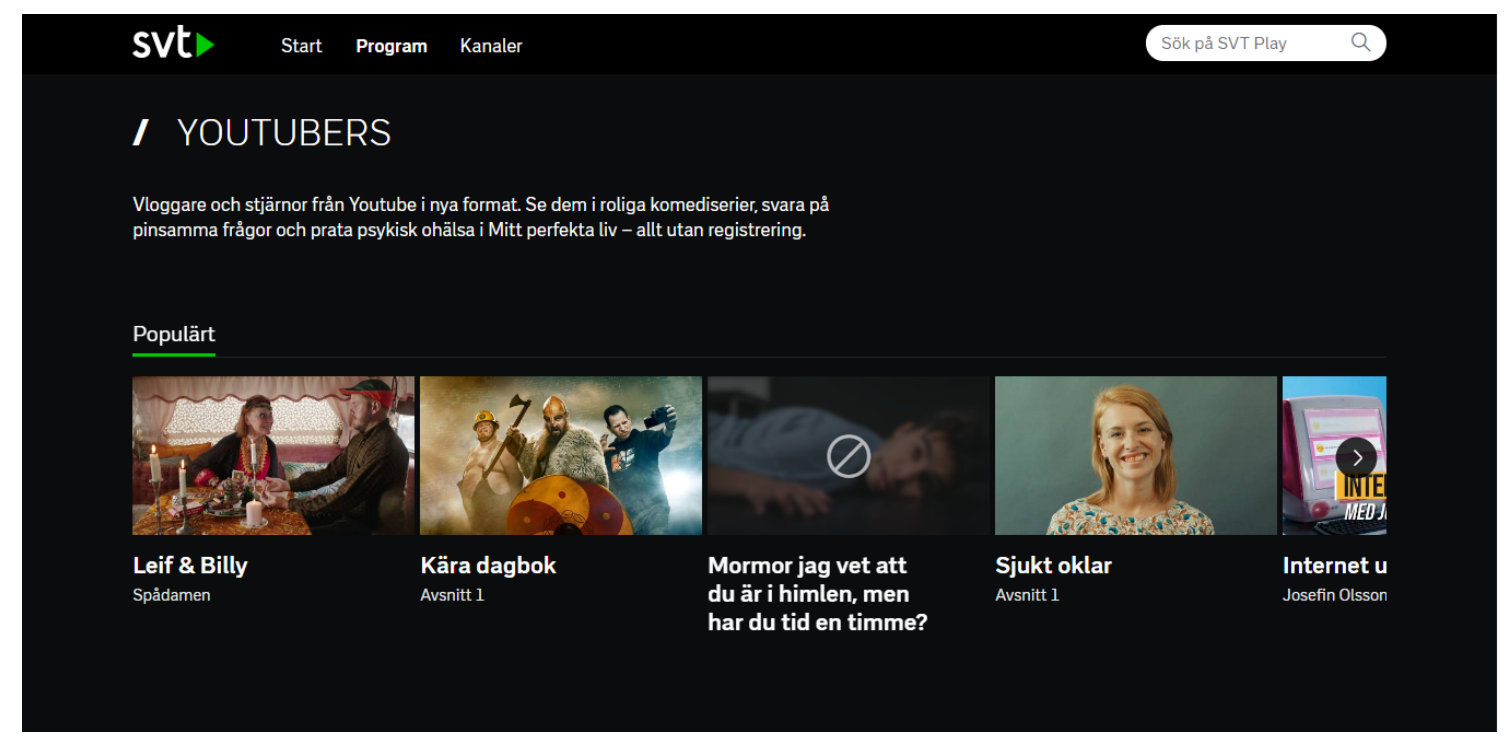

Fuente: https://www.svtplay.se/genre/Youtubers

En Reino Unido la British Broadcasting Corporation (BBC) convirtió el canal BBC Three en un canal de transmisión online, transformando la oferta de la televisión pública inglesa para los jóvenes. Los contenidos se pueden visualizar en iPlayer, la web de visualización online de los contenidos de la BBC y en la plataforma The Best Of. También a través de la app The Daily Drop.

En BBC Three los usuarios encuentran contenido de largo formato, pero también una nueva oferta con un flujo diario de contenido que incluye cortometrajes, animación, blogs y noticias publicado a través de la plataforma The Daily Drop, en el canal de YouTube de BBC Three y en las redes sociales Facebook (3.247.341 seguidores), Twitter (13.555 seguidores), Instagram (162.045 seguidores) y Snapchat.

A la hora de visualizar los contenidos la plataforma iPlayer ofrece la posibilidad de registrarse para añadir contenido a listas, recibir recomendaciones y reanudar la visualización de un episodio o serie justo donde lo dejó el usuario. Además, permite descargar el contenido y ofrece la posibilidad de compartirlo en redes sociales y copiar el enlace para poder agregarlo donde desee el usuario. 
Figura 13. Captura de pantalla de BBC Three de la $B B C$.

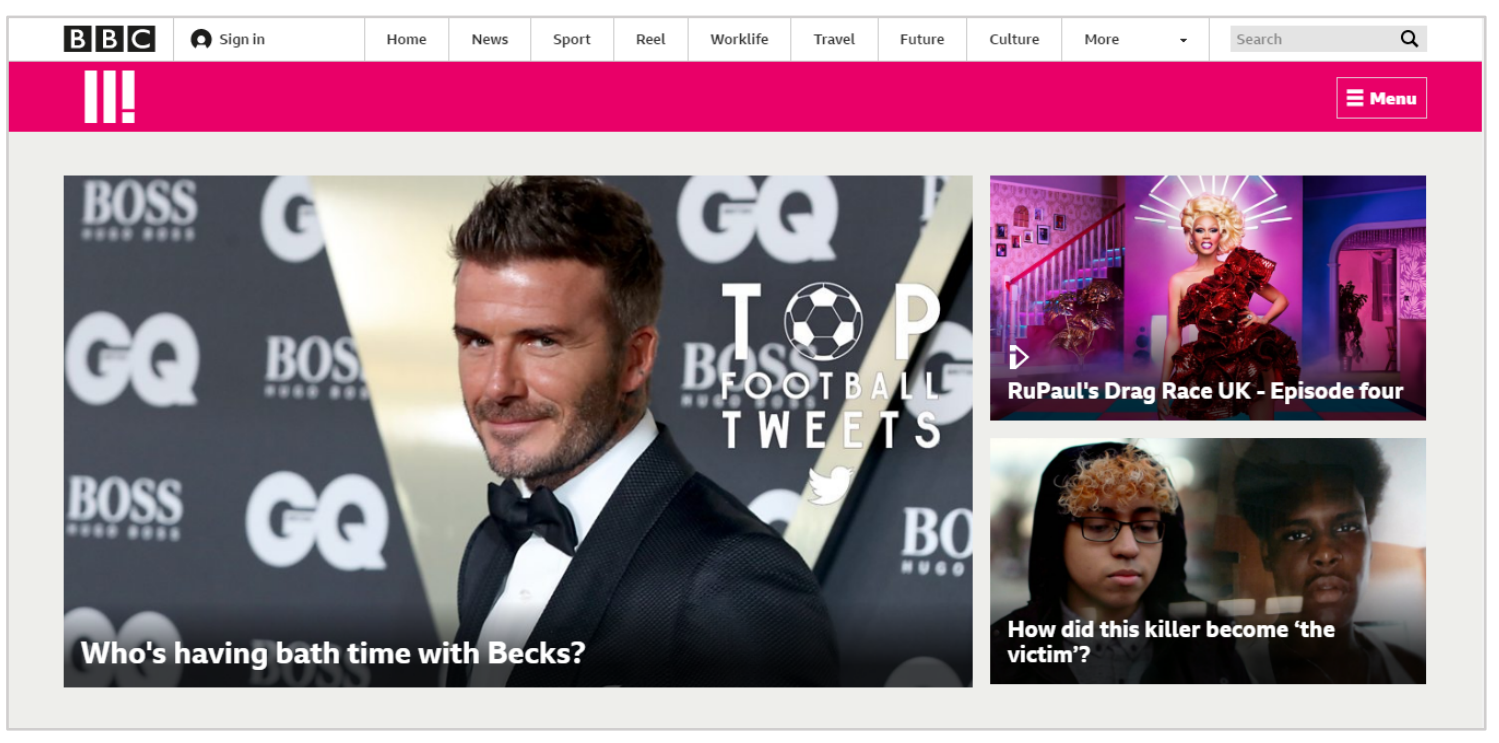

Fuente: https://www.bbc.co.uk/bbcthree

La BBC cuenta también con la plataforma Taster, definida como la casa de la BBC para las nuevas ideas, donde nuevos creadores pueden enviar sus productos e ideas.

La radio televisión Suiza (RTS) también está sumergida en un proceso de innovación, desarrollando nuevas estrategias para adaptarse a los hábitos de consumo de su público más joven a través de Internet y las redes sociales, llevando a cabo diferentes webseries que se localizan en su página web y también en YouTube.

Tataki ha sido la última plataforma desarrollada por RTS, lanzada en 2017 y basada en nuevos formatos. Dirigida especialmente a los jóvenes de entre 15 a 24 años, Tataki ofrece contenidos variados, desde series webs, narraciones interactivas o transmedia. Tataki cuenta con nuevos talentos emergentes, YouTubers, periodistas y profesionales del sector que desarrollan vídeos específicamente para las siguientes redes sociales: YouTube (18.800 suscriptores), Facebook (51.436 seguidores), Instagram (27.904 seguidores) y Snapchat. 
Figura 14. Captura de pantalla de Tataki de RTS.

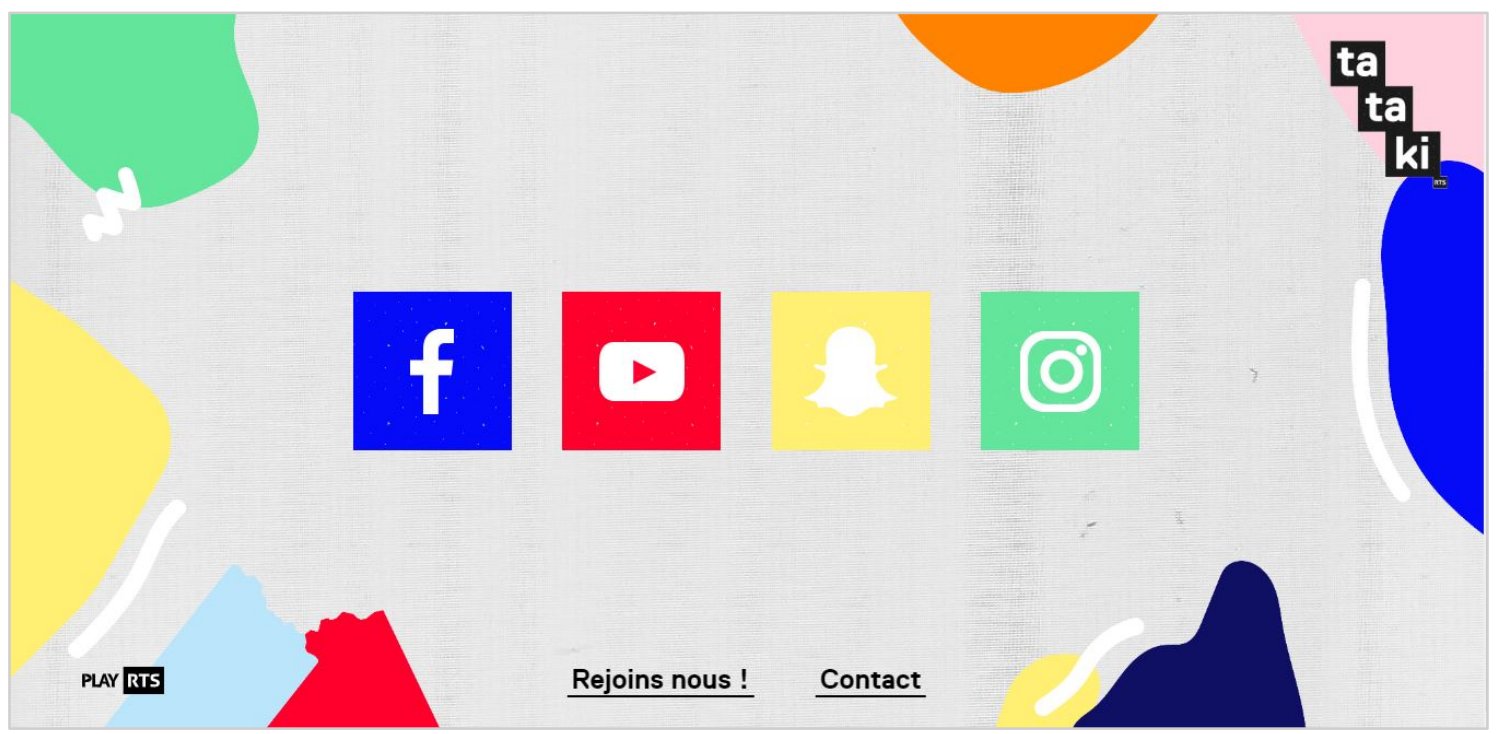

Fuente: https://www.tataki.ch/

\section{CONCLUSIONES}

La convergencia tecnológica ha propiciado numerosos cambios en los modos de producir, distribuir y promocionar los contenidos audiovisuales, al mismo tiempo que supuso un cambio transcendental en los hábitos de consumo de los espectadores. Ante estas circunstancias, las corporaciones de radiotelevisiones públicas europeas desarrollan estrategias para conseguir adaptarse a estos entornos emergentes y atraer a las audiencias que ya no ven la televisión de forma lineal, sino que buscan interactuar y participar en los contenidos que visualizan.

Diferentes grupos corporativos han desarrollado plataformas con contenidos digitales y originales para acercarse a las nuevas generaciones de espectadores, que cada vez consumen menos la televisión lineal en busca de una innovación en los contenidos que ven. La creación de contenidos originales, adaptados a las narrativas y lenguajes propios de Internet y la apuesta por nuevos creadores de corta edad, definen la apuesta principal de las plataformas objeto de estudio. La participación con los contenidos se produce a través de las redes sociales de moda, sobre todo a través de Facebook e Instagram, red social que cada vez más se utiliza como una plataforma de desarrollo del propio contenido. 
Se ha podido comprobar que, a pesar del número de plataformas con estas características, aún quedan muchas televisiones públicas que no desarrollaron esta oferta, no obstante, se pudo comprobar durante el análisis cómo se está trabajando en este sentido, adaptando la oferta a los nuevos hábitos de consumo de las audiencias, a través del desarrollo de algunos contenidos experimentales a través de las redes sociales o sus páginas webs, como es el caso de la televisión pública de Israel que ha desarrollado un apartado digital con programas en red para visualización directa y ha creado el espacio "The Artist's house " donde recibe propuestas e ideas de nuevos creadores. Informes recientes como el de Ofcom sobre la BBC (2019) evidencian la desconexión de la audiencia joven respecto a las televisiones públicas europeas, por lo que la puesta en marcha de estos canales nativos digitales es una de las líneas estratégicas emprendidas por estos canales para combatir su vulnerabilidad en el entorno audiovisual actual y futuro.

\section{REFERENCIAS BIBLIOGRÁFICAS}

Albújar, M. (2016). Las plataformas OTT para la distribución de contenidos audiovisuales: ¿una amenaza para el duopolio de la televisión en abierto en España?. Quaderns del CAC, 9(42), 21-28. Recuperado de https://www.cac.cat/sites/default/files/migrate/quaderns_cac/Q42_ES.pdf

Arceo, G.M. (2017). Traditional and New Media Convergence on Philippine Noontime Show, Eat Bulaga. SHS Web of Conferences. 0019(33), 1-7.

https://doi.org/10.1051/shsconf/20173300019

Barlovento Comunicación. (2016). Los Millennials y la TV: Qué programas ven y cómo consumen. Recuperado de https://www.barloventocomunicacion.es/wpcontent/uploads/2016/10/informe Barlovento MILLENNIALS oct16.pdf

Codina, L., y Sánchez, N. (2008). Propuesta nuclear de análisis de sitios web de televisión. Departamento de Comunicación Universitat Pompeu Fabra. Recuperado de https://www.lluiscodina.com/propuesta-nuclear-de-analisis-de-sitios-web-detelevision/ 
Crusafón C. (2011). Las nuevas plataformas digitales: análisis de las estrategias desarrolladas por los informativos de las networks estadounidenses ( $A B C, C B S$ y NBC) y de las cadenas temáticas (CNN, Fox News y MSNBC). En A. Casero, y J. Marzal (Eds.), Periodismo en televisión. Nuevos horizontes, nuevas tendencias (pp. 140-155). Zamora: Comunicación Social Ediciones y Publicaciones.

Deloitte. (2019). The Deloitte Global Millennial Survey 2019. Recuperado de https://www2.deloitte.com/content/dam/Deloitte/global/Documents/AboutDeloitte/deloitte-2019-millennial-survey.pdf

Dimock, M. (2019). Defining generations: Where Millennials end and Generation Z begins. Pew Research Center. Recuperado de https://www.pewresearch.org/fact$\underline{\operatorname{tank} / 2019 / 01 / 17 / \text { where-millennials-end-and-generation-z-begins/ }}$

Fernández-Planells, A., y Figueras-Maz, M. (2014). De la guerra de pantallas a la sinergia entre pantallas: El multitasking en jóvenes. En A. Huertas, M. Figueras (Eds.), Audiencias juveniles y cultura digital (pp. 87-105). Bellaterra, Barcelona: Institut de la Comunicació. Universitat Autònoma de Barcelona.

García-Carrizo, J. (2016). Análisis de la página web del canal Antena 3: oferta de contenidos, interactividad y redes sociales. Revista Mediterránea de comunicación. 7(2), 117-140. https://doi.org/10.14198/MEDCOM2016.7.2.11

González-Neira, A. y Quintas-Froufe, N. (2016). El comportamiento de la audiencia lineal, social y en diferido de las series de ficción españolas. Revista de la Asociación Española de Investigación de la Comunicación, 3(6), 27-33. Recuperado de http://revistaeic.eu/index.php/raeic/article/download/63/68

González-Neira, E. (2015). La otra pantalla. Redes sociales, móviles y la nueva televisión. Barcelona, España: Editorial UOC.

Guerrero, E. (2018). La fuga de los millennials de la televisión lineal. Revista Latina de Comunicación Social. 73, 1231-1246. Recuperado de http://www.revistalatinacs.org/073paper/1304/RLCS-paper1304.pdf 
Howe, N., y Strauss, W. (2000). Millennials rising. The next great generation. Nueva York: Vintage Books.

Kantar Millwardbrown. (2017). AdReaction, Gen X, Y and Z. Recuperado de https://www.millwardbrown.com/adreaction/genxyz/

Ofcom (2019). Ofcom's anual report ont the BBC. Recuperado de https://www.ofcom.org.uk/ data/assets/pdf file/0026/173735/second-bbc-annualreport.pdf

Operating Eurovision and Euroradio. (2019). Members (70) of the European Broadcasting Union (56 countries). Recuperado de https://www.ebu.ch/about/members

Prado, E. (2015). Indispensabilidad de la televisión pública en el universo convergente. En J.J. Marzal, J. Izquierdo, A. Casero-Ripollés (Eds.), La crisis de la televisión pública: el caso de RTVV y los retos de una nueva gobernanza (pp. 39-59). Barcelona, España: Universitat Autònoma de Barcelona.

Prensky, M. (2001). Digital natives, digital immigrants. On the Horizon, 9(5), 1-6. https://doi.org/10.1108/10748120110424816

Quintas-Froufe, N. y González-Neira, A. (2014). Audiencias activas: participación de la audiencia social en la televisión. Comunicar, 22(43), 83-90.

https://doi.org/10.3916/C43-2014-08

Rodríguez-Martínez, R., Codina, L., y Pedraza-Jiménez, R. (2012). Indicadores para la evaluación de la calidad en cibermedios: análisis de la interacción y de la adopción de la web 2.0. Revista Española de Documentación Cienfíca, 35, 61-93. Recuperado de http://redc.revistas.csic.es/index.php/redc/article/view/724/804

Scolari, C. A. (2008). Hacia la hipertelevisión. Los primeros síntomas de una nueva configuración del dispositivo televisivo. Revista académica de la federación latinoamericana de facultades de comunicación social, diálogos de la comunicación, 77, 1-9. Recuperado de https://dialnet.unirioja.es/servlet/articulo?codigo=2694422 
Smartme Analytics. (2017). La Generación Z, más activa en redes sociales que los Millennials. Recuperado de 2018 de

http://smartmeanalytics.com/blog/2017/12/12/la-generacion-z-mas-activa-en-redessociales-que-los-millennials/

Smith, A. (2018). Pursuing Generation Snowflake: Mr. Robot and the USA Network's mission for millennials. Television \& New Media, 20(5), 443-459.

https://doi.org/10.1177/1527476418789896

Syvertsen, T. (2006). Television and Milti-Platform Media Hybrids: Corporate Strategies and Regulatory Dilemmnas. En F. Marcinkowski, W.A. Meier, J. Trappel (Eds.), Media and Democracy: Experience from Europe (pp. 253-273). Bern: Haupt Verlag. 